\title{
A crise
}

\author{
Rafael Voigt Leandro ${ }^{1}$
}

Entretinha-se com filmes da televisão. Praguejava em demasia contra os excessivos comerciais. Não comprava nada daquilo. Às vezes, emocionava-se com os jingles publicitários dos bancos privados. Sentia que poderia ser melhor. Não por causa da vontade de se entregar aos apelos da menina do telemarketing que lhe oferecia diversas vantagens se aceitasse um dos cartões de crédito. Quantas vezes pediu para alguém dizer que ele não morava ali. Um dia, enfureceu-se por besteira com uma dessas inocentes mulheres. Não me ligue mais. Será que você não entende que eu não quero essa porcaria?!... E bateu o telefone na cara dela. Irritado, não podia mais continuar na cama. Todo sábado, costumava dormir até as dez. Nos dias de trabalho, acordava quinze para as seis da manhã. Não achava justo o importunarem com ligações inúteis. Quando sobreveio a crise do ano passado, preocupou-se com o aumento dos preços das coisas. A derrocada de uma instituição financeira jogava pessoas inocentes na lama. Escutou essas palavras de um comentarista do jornal das oito. Sabia que sofreria em breve a pressão de todos os lados. Pressão de viver com cuidado. Cuidado de não extrapolar nas compras do mês. Comprar frutas nobres, nem pensar. Damascos e kiwis ficariam na memória. Pretendia trocar de carro. Pelo visto, um sonho adiado. Ladainhas ouvidas com freqüência na voz do economista diversas vezes entrevistado no programa de rádio. Tinha visto a cara dele até em portais de notícias da internet. Só porque ele havia sido ministro da economia uns vinte anos atrás. O mundo já é outro. Precisamos comprar carne pro almoço de domingo. Sentiu o peito disparar quando ouviu o reclame da mulher. Não entendia por que fora afetado daquela maneira. O coração disparar? Estranho... Como podia fatos até ontem tão alheios à minha vida me importunarem agora? Pensava. A mulher achou estranho ele ficar mudo sem razão. Claudiano era homem falador. Suas respostas, como costumava repetir, tavam sempre em cima da língua. Calou-se. Você me ouviu? O que aconteceu? Viu que não era possível fugir aos apelos da esposa. Escutei. Tô pensando se não podemos oferecer outra coisa pro pessoal. Toda vez que eles vêm aqui, a gente coloca carne no prato. Se a gente fizer um

\footnotetext{
${ }^{1}$ É licenciado em Letras-Português pela Universidade de Brasília (UnB). E-mail: rafael.letras@gmail.com
} 
macarrão... Sílvia ficou calada. Jamais o marido discutia a respeito do que fazer para o almoço de domingo. Apenas dava o dinheiro. Pode ser uma macarronada... ou uma galinhada. Talvez galinhada seja até melhor. Rende bastante... Ela não concordava com Claudiano. Tentou se contrapor. Mas ele emendou: Vou sair agora pra comprar tudo. $O$ pessoal vai adorar a galinhada de domingo. Vão lamber os dedos. Antes de o marido sair, Sílvia conseguiu ainda dizer para ele não esquecer de comprar refrigerantes.

Em baixo do prédio, havia uma banca de jornais. Parou por um instante. Procurou a revista semanal. Caramba, mais de 600 milhões de dólares em dívidas. Não escondeu a surpresa. Seu Neto, dono do estabelecimento, riu de Claudiano. Viu aí? Engraçado isso, não? A gente se lascando de trabalhar e agora mais essa. Você vai ver, vai todo mundo sentir os efeitos disso. A quebradeira começou anteontem. Amanhã, o presidente vai falar que o Brasil tá salvo. Pra ninguém ficar com medo, o comandante da nação vai pedir pra todo mundo não parar de comprar. A economia tem que circular... Claudiano não prosseguiu a conversa. Duvidava das palavras do jornaleiro. Deu um tchau incômodo. Um professor universitário havia afirmado a um repórter da tevê que o Brasil, semana que vem, iria sofrer os efeitos da crise. Ela não vai demorar a chegar por aqui. Claudiano concordava com o professor. Afinal, os argumentos dele eram muito mais lógicos que os de seu Neto. Aquele acadêmico havia estudado tanto pra aquilo. Sua visão macroeconômica era mais precisa. Não se restringia a jornais e revistas. Seu Neto tem sempre aquele ar de sabichão. Não sabe de nada. Um palpiteiro de primeira classe. Acho que não perde nem pros taxistas. É muita lorota ao mesmo tempo. Analisam o país sem estudar porcaria nenhuma. Saiu pela calçada tropeçando em alguns paralelepípedos. Desde criança, andava arrastando os pés. Não desaprendia. Muita gente passava na frente da banca com pressa também. Sequer aquela gente olhava as notícias. Alguns tinham um celular na orelha e uns óculos escuros para esconder seus olhares inquietos. Outros paravam para comprar créditos para celular e qualquer tablóide de cinquienta centavos. Claudiano entrou em uma agência bancária. Não resistiu à tentação de saber qual era seu saldo. Tirou os óculos da cara. Olhou com cuidado os números. Semana passada, recebi o pagamento. Hoje, tô apenas com a metade no bolso. É como se eu tivesse sido assaltado. Não adianta pagar em várias vezes. O juro come solto. Em março, acabo de pagar o armário da sala e a 
televisão do quarto. Acho que vai aliviar. Talvez seja isso. Ou, quem sabe, a crise já tenha chegado pra mim.

Empurrou a porta giratória. Atravessou a rua. Misturou-se aos clientes do supermercado. Filé de frango, kilo, por apenas... Arroz tipo A... Refrigerante, 2 litros, por... Faça o cartão da loja e receba muito mais descontos em suas compras. Boa tarde! Boas compras! Achou esquisito o locutor repetir a palavra compras. Suas compras... Boas compras! Procurou a seção açougue. Olhou o preço do frango e afastou-se do freezer. Pegou o celular. Alô, Sílvia... Quantos frangos a gente precisa pra galinhada? Uns cinco?... A interlocutora disse apenas: É, pode ser. Claudiano nunca sabia a quantidade ideal de cada receita. Não era ele quem preparava a comida. Nem mesmo Sílvia. Isso era tarefa de D. Domingas. Colocou os frangos num carrinho vazio. Dirigiu-se à ala dos refrigerantes. Novamente telefonou para casa. Sílvia ficou um pouco irritada com as incertezas do marido: Sei lá. Pega quatro. Acho que ainda temos três na despensa. Agora, tô saindo pro salão da Gilda. Preciso fazer as unhas. Se precisar de ajuda, chama a Domingas.

Toda sexta-feira, Sílvia saía para se embelezar. Não considerava de bom-tom apresentar-se desarrumada num fim de semana. Há dez anos, conhecia a Gilda. Costumava chamá-la de Gil. No Salão Fantasia, Sílvia aproveitava para relaxar. Confessava qualquer amargura da vida com a velha amiga. Chegou ao estabelecimento por volta de três horas da tarde. A amiga não havia chegado ainda. Somente duas funcionárias estavam naquele momento. Nesse caso, como de costume, ela ficaria esperando Gil. Não entregaria suas unhas a qualquer uma. Olhou-se no espelho. Corrigiu o penteado. Retocou a maquiagem da sobrancelha. Sorriu um sorriso de mentira. Certificou-se se borrões de batom não haviam pintado seus dentes recémclareados. Tava tudo jóia. Se desse tempo, corrigiria a sobrancelha. Bom dia! Silvinha, você por aqui? Que bom revê-la, amiga! E então... Gil entrou inesperadamente. Oi, querida! Vim fazer as unhas. O esmalte já tá saindo... Sabe, todo cuidado é pouco. A cabeleireira depositou sua bolsa de couro na mesa de seu escritório, em um quarto contíguo ao salão. Balançou os braceletes. Rompeu pelo reposteiro, deslizou os dedos por cima do cabelo. Sílvia, vai ser só as unhas mesmo? Tamos com uma promoção pra quem fizer pé, mão e cabelo. É a metade do preço normal o pacote. Se você quiser aproveitar. A promoção vai até sexta-feira da próxima semana. Vou colocar uma placa 
lá fora. Não sei por quê, mas o movimento neste mês ficou mais fraco. Tô estranhando. Duas clientes ontem me ligaram pra desmarcar. Hoje cedo, uma ligou no meu celular e também desmarcou. Perguntei o porquê. Ela me disse apenas que o marido havia sido demitido da empresa e que agora teria que poupar um pouco mais. Parece que o homem trabalhava lá havia quase treze anos. Não entendo como de uma hora pra outra manda o pessoal embora. Essas minhas meninas trabalham há cinco anos aqui no salão. Se depender de mim, continuam comigo pra sempre. Só se acontecer algum problema muito grave... Se uma delas trair minha confiança ou quiser mudar de emprego. Até o final do ano, acho que vou contratar mais uma...

Gilda emendava uma conversa na outra. Enquanto ouvia a amiga, Sílvia tirou uma revista do revisteiro para ver os modelos de corte. Folheou ao acaso. Não se julgava muito disposta a cortar o cabelo. Dia de lua cheia não era propício. Poderia ter problemas com a aparência futuramente. Recusaria a promoção. Mas, repensou. A amiga poderia ficar chateada. Como não aceitar uma liquidação daquela? Gil desconfiaria. Acreditaria que Silvinha estava com má vontade. Claudiano não concordaria com aquele gasto, mesmo que fosse pela metade. Teria que dispor de um dinheiro razoável. Ele estava preocupado com as contas. Percebeu quando ele assistia ao primeiro jornal da manhã. A intenção de preparar um prato alternativo para o almoço de domingo denunciou a preocupação do marido. A evidência clara de que ele temia o encolhimento salarial. Era natural que acontecesse isso. Nos anos 80, no início do noivado, as sucessivas instabilidades financeiras fizeram a mesma coisa na vida deles. Era nos tempos do Sarney. O povo não levava muita fé naquela mudança. Se fosse o Tancredo, as coisas teriam sido diferentes. E virava as páginas. O pensamento de Silvia trafegava entre o presente e o passado. Lembrou de seus dezoito anos. Em 15 março de 1985, bem no dia de seu aniversário de dezoito anos, José Sarney tomou posse. Achavao esquisito. Os presidentes sempre tinham aquela cara meio encerada, sem bigode. Considerava esquisito aquele bigode preto e fios grisalhos na cabeça. Na memória, conservava as notícias sobre o congelamento de preço, as inúmeras remarcações, a mudança de cruzeiro pra cruzado. Paralisou sua rememoração no momento em que Gilda pegou o controle remoto e ligou a televisão que ficava na quina superior da parede. De março a agosto, o Lehman Brothers perdeu mais de 6 bilhões. O Governo dos Estados Unidos estuda a possibilidade de ajudar financeiramente a instituição. Se a 
ajuda do Governo não vier, os agentes... Vem aí a nova novela das Oito... No time do Fluminense, apenas Cleison continua na zaga... Basta colocar duas xícaras de azeite e refogar... Agora, é saber se o quarto maior banco dos Estados Unidos continuará de pé após a concordata... Gilda não sabia em que canal deixar. Preferiu sintonizar no jornal. Silvinha, se quiser sentar aqui, pode vir. Tô pronta. Podemos começar...

Claudiano emburrou-se na fila. Dez pessoas na frente... Por que não abriam os outros caixas? Apenas dois funcionando um horário desse? Como pode? Querem vender mais, mas não sabem... seria muito mais fácil se colocar mais caixas, gente. Vou falar com o gerente. Eles pensam que a gente tem o dia todo pra ficar aqui plantado nessa fila... Quem é o gerente?... Deve ser aquele de blusa listada com o emblema do supermercado... Ei, vem cá! O homem dirigiu-se a Claudiano com o passo veloz. Tudo bem?... Vocês pensam que a gente tem o dia inteiro pra ficar plantado aqui nessa fila? Tem dez pessoas na minha frente! E espalmava as duas mãos no ar, perto da cara do rapaz. Duvido se o senhor agüentaria mais de vinte minutos... Meio espantado, o homem fez uma cara de perplexidade. Meu senhor, levarei sua reclamação ao gerente... Infelizmente, não temos funcionários suficientes pela manhã. A procura é menor nessa parte do dia... Compreendo sua situação, mas peço paciência... Eu sou apenas o encarregado pela segurança. O gerente não tá no momento... Claudiano dispensou o homem. Não queria ouvir mais desculpas. Deixou-se consumir por pensamentos convulsos. Tudo mentira. O gerente devia estar lá no escritório só contando dinheiro. Estratégia de defesa. O segurança fica aqui embaixo e o gerente se eximindo das culpas. Ele nem sabe que eu existo. Que besteira. E o dono? Onde estaria o dono agora? Dentro de casa, não há dúvida. O problema dele não é dinheiro, não é tempo, não é nada. Deus sabe o que faz. Ele vai pagar tudo isso. Dinheiro não compra a felicidade. D. Domingas repetia isso com insistência. Não podia ver uma coisa ruim na televisão recorria àquela frase. Se não fosse essa, afirmaria: Se Deus é por nós, quem será contra nós? Claudiano, impaciente, refletia de modo desconexo. Passaram-se mais vinte minutos. Já era o segundo da fila. O carrinho da senhora da frente aparentava superlotação. Compras do mês? Não podia ser. Provavelmente, compra bimestral. Estocar comida por tanto tempo? Pra quê? Bobagem. A crise assustou o povo. Ninguém podia ouvir a palavra crise que tomava medidas de precaução. Armazenar comida não resolve. Em tempos de crise, sempre comemos mais. De nervoso. Todo mundo vai enfrentar. Tem que encarar 
essa realidade. Seus pensamentos desconexos cessaram quando a senhora preencheu o cheque e entregou para a mulher do caixa. Bom dia, senhor! Qual vai ser a forma de pagamento?... Claudiano respondeu que seria com o cartão de crédito. Senhor, infelizmente o sistema tá fora do ar. O senhor tem como pagar de outra forma?... O cliente, prestes a explodir em fúria, pegou a carteira. Não encontrou cédulas suficientes. Enfiou a mão no bolso da calça jeans, mas não encontrou as moedas para completar. Nervoso, só lhe veio uma idéia. Espere um momento, moça... Vou ligar pra minha mulher. Vou verificar se ela pode vir até aqui com o dinheiro. Senão, terei que cancelar a compra. Discou os números rapidamente.

A bolsa de Sílvia repousava sobre o balcão embaixo do espelho. É, Silvinha, mas no casamento nós temos sempre algum probleminha. Me lembro do meu finado marido Valdomiro. Às vezes, por qualquer motivo, discutíamos. Teve um dia que coloquei uma roupa mais confortável e ele disse que aquilo não era direito. Andar daquele jeito não condizia com mulher de família. E eu nem pretendia sair com aquela roupa pela rua. Era só pra ficar dentro de casa. Por coisa mínima, a gente brigava. Não fica assim, não, amiga. Isso se resolve. Vocês se gostam. Dá pra perceber... Quando Gil proferiu o final de sua fala, Sílvia estremeceu. A pele enregelou-se. Fazia tempo que não sentia aquele sentimento. Com tantas rusgas com o marido, não dava para avaliar se realmente o amava. Eram tantas as pendengas do dia-a-dia. Eram tantos problemas que surgiam. Esses fatos atrapalhavam o amor. Gostava, sim, de Claudiano. Tinha quase certeza. Pronto. Terminei. Não quer mesmo fazer o cabelo hoje? Quando a gente deixa as coisas pra depois, a gente acaba perdendo. Vamos aproveitar agora. Como falam por aí: quem sabe faz a hora, não espera acontecer... Sílvia não ponderou muito. A lua cheia no céu e sua negativa na terra. Até riu, quando vieram essas idéias. Decidiu dizer. É, Gil... é a lua cheia no céu e o meu não na terra. Hoje não vai dar, amiga. Não vai dar mesmo. Não fique chateada. Na próxima sexta, eu volto. A gente conversa mais. Vou seguir seus conselhos. Meu casamento vai melhorar e muito. Pegou a bolsa. Tirou a carteira, pegou o talão de cheque, começou a escrever o valor. A cabeleireira levou o cheque até seu quartinho. Depositou-o em uma das gavetas. Trocaram beijos, abraços e se despediram. Silvinha saiu pela rua, sentindo o frescor do vento pelas unhas.

A mulher de Claudiano não demorou para chegar em casa. Quando abriu a porta, viu uma lata de cerveja aberta em cima da mesa de jantar. O som do rádio estava alto.... 
Se eu tô devendo dinheiro e vem um me cobrar. Dotô, a peste abre a porta e ainda manda sentar... Desligou o rádio. Aquela zoada incomodaria os vizinhos. Daqui a pouco, o síndico bateria aqui. Isso é coisa de Claudiano. Onde ele tá? O marido saía do banheiro. Por que você desligou o som? Ficou louca?... Onde você estava esse tempo todo? É a tarde inteirinha pra fazer a unha? Nunca vi isso. Você levou seu celular? Eu te liguei milhares de vezes! E você nem atendeu... Eu tava precisando de você. Se você não sabe, não tem porcaria nenhuma pra gente comer no domingo. Não comprei os frango nem os refrigerante. Sabe por quê? Porque você não atendeu o telefone. Não tem tempo pra isso, não é? Deve ter falado: "Deve ser o enjoado do meu marido. Não vou atender." E eu precisando de um favor fácil seu. A droga do cartão não tava passando lá no supermercado. E eu sem um tostão no bolso. Era só pra você ir lá entregar o dinheiro. Nada mais. Mas você não tem tempo. Não tem tempo pra nada. É sempre a mesma coisa. Passei uma vergonha monstro. Todo mundo me olhando. Todo mundo me julgando. E eu lá... Liguei trezentas vezes pra você!...

A fúria de Claudiano não cessava. Sílvia o interrompeu, tentando remediar o caso. Desculpa! Desculpa, amor! Eu não ouvi o celular. Ele tava apenas no modo vibrar. E ainda dentro da minha bolsa... Não adianta ficar nervoso. Agora já passou. Por qualquer motivo, você fica nervoso. Não pode ser assim. Você não era assim. Nunca foi assim. Bebendo por esse motivo? E fazendo essa bagunça toda em casa. $O$ que os vizinhos vão falar da gente? Você não se preocupa com as aparências. Você não se preocupa com nada. Vive reclamando. Antes, você dava dinheiro sem cobrar justificativas. Agora, tudo mudou. O que tá acontecendo entre a gente?... Claudiano riu de nervoso Como é que é? O que tá acontecendo? Não tem qualquer problema a resolver. Como você disse, agora já passou. Então, se passou, não tem mais o que se fazer. E, quanto ao controle do dinheiro, eu tô controlando mesmo. A crise, se você não sabe, vem aí com força total. Não vai perdoar ninguém. E eu não tô falando isso porque tô bêbado, não. Uma latinha não me altera em nada. Falo isso porque tô acompanhando os jornais. Existe um banco de um grupo de irmãos dos Estados Unidos que quebrou. As economias são todas ligadas. Se começou lá, vai rebentar pelo Brasil. O que a gente tem pra conversar é isso. Eu poderia muito bem sacar o dinheiro lá no banco e voltar pra buscar os produto no supermercado. Mas não fiz isso. Sabe por quê?? Porque gastar numa hora dessa é entrar de jeito na crise. Eu não quero me acabar em 
dívidas. É bom poupar. Por causa disso, repensei. Não poderia levar os frango e refrigerante. Nossos amigos, se são amigos de verdade, vão compreender. Não vamos ter mais almoços sociais aos domingos. Chega de reuniões desnecessárias. E já vou dizendo, acho que não vou poder mais bancar suas idas semanais ao salão da Gilda. Dinheiro que é bom tá em falta, minha amiga... D. Domingas atravessou a porta da cozinha. Não admitia ver o casal discutir. Porém, considerou melhor não interferir. Recordou-se do provérbio popular: da discussão, nasce a luz. Preferiu voltar a seu local de trabalho. Enxaguou as mãos. Lembrou, novamente, que dinheiro não compra a felicidade. Fingiu trabalhar. Nos culto dos casais, a irmã Jerônima não cansava de repetir que é melhor a reprimenda aberta do que o amor encoberto. Os golpes do amigo são leais, e mentirosos os beijos do inimigo. A irmã Jerônima conhecia como ninguém a Bíblia do meu senhor Jesus Cristo. A igreja promovia o encontro dos casais. Seu Claudiano e Dona Sílvia se amigariam de novo. Uma vez por semana os encontros. Sábado, eles não fazem muita coisa. Acordam tarde e saem pra almoçar. Por que não acordar mais cedo e salvar o relacionamento? Se fossem lá, se renovariam como água do rio. Creio que, se tivesse uma criança nessa casa, eles iam ser diferentes. Mas nenhum quer ver criança. Se Jesus fizer o milagre das núpcias de Cana na vida do casal, a cor do casamento muda. Era impossível não lembrar dos ensinamentos da irmã Jerônima. Que mulher fervorosa! Nem sei se já foi casada um dia. Eu nunca vi os patrões rezarem. O livro sagrado em cima da instante fica só comendo poeira. É hora de abrir o livro. Essa casa precisa de oração. Vou pedir ao grupo da irmã Jerônima abençoar esses dois. Vou colocar os nomes deles no meu caderninho de orações. Faz bem. Tá na hora dessa situação mudar. Deus me perdoe, mas isso virou um inferno. Quase toda hora esses dois se estranham. D. Domingas continuou ouvindo as vozes em desatino. (...) Ah, então, tá... Já que você veio com essa crise do dinheiro. Você vai acumular mais uma: a crise do casamento... Sílvia correu para o quarto do casal. Trancou-se. Jogou-se na cama. Afundou o rosto no travesseiro. Tentou sufocar o choro. Claudiano ligou o som. Sentou-se no sofá, entornou mais um pouco da latinha. “... Se alguma pessoa amiga pedir que você lhe diga se você me quer ou não, diga que você me adora. Que você lamenta e chora a nossa separação. Às pessoas que eu detesto, diga sempre que eu não presto. Que meu lar é o botequim. Que eu arruinei sua vida. Que eu não mereço a comida que você pagou pra mim..." 